\title{
The utility of animal models of human energy homeostasis
}

\author{
Louise Thibault $^{1 *}$, Stephen C. Woods ${ }^{2}$ and Margriet S. Westerterp-Plantenga ${ }^{3}$ \\ ${ }^{1}$ School of Dietetics and Human Nutrition, Macdonald Campus of McGill University, 21111 Lakeshore Road, \\ Ste-Anne de Bellevue, H9X 3 V9 Quebec, Canada \\ ${ }^{2}$ Department of Psychiatry, Box 670559, University of Cincinnati, Cincinnati, OH 45267, USA \\ ${ }^{3}$ Department of Human Biology, Maastricht University, Maastricht, The Netherlands
}

\begin{abstract}
The prevalence of obesity among adults and children has increased steadily over the last few years worldwide, reaching epidemic proportions. Particularly alarming is the link between obesity and the development of chronic disorders such as heart disease, type 2 diabetes, hypertension and some cancers (Bjorntorp, 1997). Environmental causes of obesity are thought to include a sedentary lifestyle and an abundance of highly palatable energy-dense foods (Hill et al. 2003). Genetic factors also contribute to susceptibility to obesity, although the genetic basis of most human obesities is thought to be polygenic (Comuzzie \& Allison, 1998; Barsh et al. 2000). The present paper considers some of the animal models used to infer aspects of human obesity, with an emphasis upon their usefulness.
\end{abstract}

Animal models: Energy metabolism: Energy homeostasis

\section{What constitutes an appropriate animal model?}

An animal model ideally mimics in as close a manner as possible a particular behavioural or physical trait of man. Hence, animals that might serve the purpose are those with comparable neuroendocrine controls over food intake or energy expenditure, variables of adipocyte physiology and metabolism, digestive systems, susceptibility to metabolic disorders or other traits thought to be important in man. That said, it is a historical fact that small rodents, rats and mice have been the predominant models of human energy homeostasis and obesity.

Phylogenetically, rats and mice are not closely akin to man. They are not as closely related as, for example, social carnivores that might mimic hunting early man (Alcock, 1979), nor as close as the savannah primates, which, like early man, were gatherers (De Vore, 1971). On the other hand, rats and mice, like man, are general omnivores, eating and deriving energy from a broad spectrum of possible foods. Consistent with this, they share similar complex taste and digestive systems for identifying and utilizing a wide range of edibles. They are also similar neuroanatomically, especially with regard to hypothalamic, limbic and brainstem systems. For the most part, manipulations of hormones or neurotransmitters, or damage to specific brain areas, elicit comparable changes in food intake and body weight of human subjects and these small rodents. That said, there are certainly differences as well. Rats, for example, have no gall bladder and are unable to store bile, and they cannot vomit to expel toxic substances from the stomach, but these are generally considered to be minor differences. If one wished to model vomiting, for example, there are more suitable animal models, such as the ferret.

There is another distinct advantage to the use of small rodents and especially mice. In this age of molecular biology, it is relatively easy to manipulate a gene in a mouse that is thought to have a homologous role in man. Their short generation time coupled with the vast knowledge of their genome makes them an especially valuable tool at the present time (Seeley \& Moran, 2002). In fact, the field of molecular genetics has advanced to the point that other quite different species, such as fruit flies (Garofalo, 2002) and roundworms (Guarente \& Kenyon, 2000), are even being used as models of certain metabolic processes in man.

An important question, therefore, is whether the species that are used are the most appropriate. To address this issue, one should ideally examine as many species as possible, from invertebrates to cold-blooded vertebrates (fish, reptiles) to mammals, from continuous to seasonal eaters (hibernators, migrators), and so on. While difficult to do, such a project could suggest physiological or psychological processes that might be unique or universal. The point is that we can learn as much from those animals that differ from man as from those that are similar. The more species we study, the more robust the general principles that are likely to emerge.

\section{Animal models of human obesity}

Human obesity is defined using the BMI (body weight $(\mathrm{kg}) /$ height $\left.(\mathrm{m})^{2}\right)$. Subjects with BMI $\geqq 25 \mathrm{~kg} / \mathrm{m}^{2}$ are classed as overweight; $\mathrm{BMI} \geqq 30 \mathrm{~kg} / \mathrm{m}^{2}$ is classed as 
obese; BMI $>35 \mathrm{~kg} / \mathrm{m}^{2}$ is generally termed morbid obesity due to the high percentage of body fat (World Health Organization, 1998). All of the metabolic complications of obesity directly correlate with the BMI, including the risk for $\mathrm{CHD}$, hypertension, type 2 diabetes and many cancers (Lebovitz, 2003). An important aspect of human adiposity is that fat is differentially distributed in and beneath the skin (subcutaneous fat) and in the abdomen (visceral fat). Females/males have relatively more subcutaneous fat and have relatively more visceral fat (Wajchenberg, 2000), and it is visceral fat that is correlated with the complications of being obese (Bjorntorp, 1997; Wajchenberg, 2000). Hence, indices other than BMI are important as health predictors in man, such as the waist circumference and/or the waist:hip ratio (Lafontan \& Berlan, 2003). An increase in either of these measures correlates highly with the risk of metabolic problems associated with obesity.

Evaluating animal models by the same criteria is not valid (i.e. there is no validated BMI or waist:hip ratio in rats or mice). Generally, animal obesity is measured by total body fat, although visceral and subcutaneous fat are more commonly assessed. Importantly, recent analyses have revealed that, as in human subjects, female rats have relatively more fat and especially more subcutaneous fat and male rats have more visceral fat (Clegg et al. $2003 b, c)$. In addition, as is the case with human subjects, the levels of hormones related to adiposity differ in male and female rats. Female rats have higher levels of circulating leptin and male rats have higher levels of circulating insulin, and the levels of both hormones correlate directly with body fat (Dua et al. 1996; Wajchenberg, 2000). However, in man, insulin but not leptin is a risk factor for the complications of obesity and the insulin resistance syndrome (Cigolini et al. 1995). Finally, the brain of female rats is more sensitive to the negative feedback control of leptin on food intake and body weight, whereas the brains of male rats are more sensitive to the negative feedback control of insulin on food intake and body weight (Clegg et al. 2003c). Rats, however, differ considerably from man in their pattern of growth. Male rats continue to gain weight throughout their lives until they are very old, whereas the body weight of female rats becomes stable in early adulthood. Human subjects of both genders have a pattern more like that of female rats.

Human obesity is a complex multifactorial condition that has been related to excessive food consumption, low energy expenditure, genetics, gender, age, socio-economic status, ethnicity, educational level, smoking status and many other factors. Intricate interactions may occur among these factors. As an example, in industrialized countries, obesity in women is more prevalent in lower than in higher socio-economic groups, whereas the opposite situation occurs in developing countries (e.g. Goodman et al. 2003). Modelling contexts or factors such as these is not easy, especially in animals.

Excessive energy intake and weight gain can be induced by the use of highly palatable, energy-dense foods and diets in rats and mice as well as human subjects (e.g. Woods et al. 2003). Likewise, changes in the brain are comparable in these species. For example, lesions near the ventromedial hypothalamus in a rat's brain induce hyperphagia and massive weight gain, paralleling what happens in human subjects with a tumour or stroke in the ventromedial hypothalamus (Bray, 1976). Lesioned rats also have lower activity levels, overeat only if the food is palatable, and are less willing to work for food than controls (for reviews, see Powley, 1977; Bray, 1984; Logue, 1991). Many of these traits appear analogous to those of some obese people. Industrialized societies often promote a sedentary lifestyle, and are characterized with a ready availability of foods geared to the preferences of the population (palatable and widely and cheaply available). There is also evidence that supports an unwillingness to work for food by obese human subjects. A series of experiments by Stanley Schachter et al. indicated that obese subjects ate more food when it was freely available, but less than lean controls when they had to perform some task to get it (Rodin \& Marcus, 1982; Schachter, 1968, 1974). The important point is that some complex behavioural traits of obese human subjects may have animal analogues.

When rats or mice are used as subjects, they are typically from controlled strains and specific breeders, and they are individually housed in small cages that limit physical activity and preclude most social interactions, in rooms controlled for temperature and humidity, and generally for the noise level as well. The room has a fixed lightdark cycle, usually $12 \mathrm{~h}$, to limit environmental stress. In most studies, food is close by and readily available all the time, so the animals do not have to work for food. Because of these conditions, the experimenter is in essentially complete control with regard to environmental factors and genetic background. While these conditions are ideal for enabling experimental control, they do not necessarily mimic the normal human condition.

\section{The ethics of using animal models of obesity}

Committees that are responsible for the ethical treatment of animals in research impose strict standards and ultimately help to establish the tight environmental control researchers impose on laboratory animals. Hence, the ethics of animal well-being help to assure healthy and stable environmental conditions, hygienic animal care, access to nutritionally adequate food and water, proper handling, pain management, and so on. Protocols that deviate from these conditions are closely scrutinized and must be justified on the basis of sound experimental need to be approved.

As the standards for animal care change, accepted conclusions based upon studies assessing food intake might also change. That is, requirements for environmental enrichment (such as placing an object in the cage, which animals can chew or play with, placing a cylinder in rodent cages to allow animals to hide or using tub or shoebox cages instead of cages with wire-mesh floors) or for group-housing animals (as opposed to maintaining them in individual cages), except in certain conditions, are changing and might lead to new insights. Although some of these environmental enrichment measures may be perceived as troublesome in feeding experiments, they lead to systematic investigation of some of these factors. For example, group housing promotes social interaction as well as increased physical activity. Indeed, social 
influences on eating are recognized in human subjects (for reviews, see De Castro, 1988; de Castro \& Stroebele, 2002), and physical activity has direct effects on energy balance.

The increasing pressures applied by animal care and use committees have other effects as well. Researchers must now explicitly justify the use of animals as opposed to using in vitro models. However, when understanding behaviour, such as food intake, is the goal of the research, in vitro or computer-modelled approaches have only very limited utility. The choice of species is also being influenced. The use of rats and mice appears to be less controversial than the use of cats and dogs, or non-human primates, thus perpetuating the trend that already exists.

A major advantage of using animal models is of course to pursue research avenues that are impossible with human subjects. For example, invasive procedures, such as gaining access directly to brain areas by means of cannulas or electrodes in order to address questions on the neural circuitry or neuropharmacology of ingestive behaviour, can only be done with animals. While less invasive techniques, such as the systemic administration of drugs like fenfluramine and amphetamine that affect food and water intake similarly to when the drugs are administered centrally (for reviews, see Thibault \& Booth, 1999b), are used in research on human subjects, most neurotransmitters and hormones do not easily penetrate the blood-brain barrier.

Most regulatory agents decree that drugs should be tested first in animals before approval is given for human trials. However, the scope of the requisite animal research may not always be sufficient to understand nuances that apply to human subjects. As an example, although a drug might be approved for human use, little might be known regarding gender or macronutrient selection effects. This was the case for Meridia (sibutramine), a drug approved by the Food and Drug Administration to treat human obesity in the USA in 1998. Only after it had been approved did human trials determine that sibutramine changes macronutrient selection, changing the relative fat:carbohydrate intake at certain times of the day (Rolls et al. 1998; Chapelot et al. 2000). This has now been replicated in male and female rats (M Leblanc and L Thibault, unpublished results), despite the fact that human subjects had a choice of food, each food containing more than one macronutrient, while the animals ate macronutrientrich dishes. Such nuances are important to identify and understand, since pharmacotherapy should be an adjunct to diet and other treatments. Man eats food for many reasons other than energy balance, and this example demonstrates how animal and human research can be coordinated to understand some of the environmental and emotional influences that can occur in man.

Can animals tell us anything about what is going on in the mind of obese individuals? On the one hand, a symptom such as overeating can be seen by direct observation and measured precisely in laboratory animals. In fact, accurate assessment of variables of intake (e.g. the precise energy contents of meals, macronutrient intake and patterns of intake) is not easy in human subjects and is subject to biases (De Castro, 1988; de Castro \& Stroebele, 2002). What cannot be easily inferred from animals is a change in the motivation to eat, although certain paradigms using animals purport to do this (Grill et al. 1996; Grill \& Kaplan, 2002; Berridge, 2004). On the other hand, most psychological attributes of human subjects can only be obtained verbally, such that language is often used to set human subjects apart in studies of ingestive behaviour.

Animals enter experiments on ingestion with limited or no experience in diverse environments or foods. Human subjects, on the other hand, enter experiments with considerable experience, and learned responses often influence their behaviour in a test situation. Learned approaches to certain situations, such as over- or undereating when one is stressed or depressed, could contribute to altered intake. For the most part, findings from animal and human investigations on the effects of learning on meal initiation have concurred (for reviews, see Logue, 1991; Woods \& Strubbe, 1994; Sclafani, 1997; HP Weingarten, unpublished results).

\section{Factors that influence food intake and obesity}

\section{Developmental factors}

Human obesity develops in the context of environmental pressures and learned food preferences, factors that are not present or minimized in animal models. In man, the development of food preferences in childhood is greatly influenced by their parents and their peers (Birch \& Fisher, 1998). When they are young, children regulate their food intake quite precisely, but this regulation becomes less accurate as children age (Birch et al. 1991; Rolls et al. 2000). Animal models that examine the factors involved in the acquisition of food and nutrient preferences are thus important, as earlier work has provided comprehensive physiological and behavioural analyses concerning the acquisition of the control of food intake in animals (Thibault \& Booth, 1999a), especially the modelling done by parent animals (Galef \& Giraldeau, 2001).

\section{Patterns and rhythms of intake}

Feeding is periodic in man and animals, with circadian influences predominating (Le Magnen \& Devos, 1982; Strubbe \& Woods, 2004). Circannual rhythms of food intake are also important, especially in hibernators and migrators (Mrosovsky \& Melnyk, 1982), and seasonal changes in intake have also been described in human subjects (De Castro, 1991). Hence, investigating the underlying phenomena in animals may help us to understand why human subjects choose to eat and drink at different times of the day, and the amounts ingested. Although some of the origins of eating and drinking patterns lie in individual habits and social norms, some reflect endogenous oscillatory drives and metabolic factors (Waterhouse et al. 1997; Strubbe \& Woods, 2004).

\section{Food choice}

In the majority of studies, animals are offered laboratory chow as their sole food source. To make a comparable 
clinical trial, subjects would have to be offered a diet consisting solely of bran cereals and milk, vitamin pills and water (or some other non-variant formula). While these diets may meet the nutritional requirements in both species, convincing human subjects to consume such a constant diet day after day would probably be met with considerable resistance. One approach has been to create more human-like experimental diets to present to animals, with two or more dietary constituents differing in nutrient content. These 'dishes' can vary in macronutrients, texture, flavour and other properties (Sclafani, 1989; Thibault \& Booth, 1999b). What is key is that whatever diet is used must ensure the nutritional adequacy of the diets used (Thibault, 2003). As an example, in rats, the protein level in the diet must be adjusted to meet maintenance and growth needs, while a minimum fat level is required to provide the essential fatty acids. Diets that induce nutrient imbalances or deficiency frequently lead to underconsumption (Gietzen \& Magrum, 2001).

\section{Genetic factors}

Obese individuals can modify their lifestyle, but they cannot change their genes. Inherited genetic predisposition has been implicated in almost all aspects of energy homeostasis, including the maintenance of body weight and the effectiveness of dietary and physical activity interventions to cure obesity (Bouchard, 1995; Rankinen \& Bouchard, 2002). However, all of these genetic factors involve multiple genes, whereas the classic animal models of genetic obesity are the $o b / o b$ and the $d b / d b$ mouse, the Zucker $f a / f a$ rat, and a few others, all of which have a single gene mutation and most of which were first described several years ago (Ingalls et al. 1950; Zucker \& Zucker, 1961; Coleman, 1978). With the identification of the obese gene and the protein leptin (Zhang et al. 1994), studies on the genetics of human obesity shifted, and leptin-resistant and leptin-deficient obese children were soon identified. Animal research rapidly identified other genes involved in the control of energy homeostasis, including the role of melanocortins and their receptors in the hypothalamus (Cone 1999) that also have human homologues (Comuzzie \& Allison, 1998; Yeo et al. 1998). Identifying central neural circuits that influence all aspects of energy homeostasis is a very active area of animal research with the promise that newly created animal models will greatly help in understanding the biology of human obesities (Woods et al. 1998; Schwartz et al. 2000).

\section{Summary}

In summary, animal models for ingestive behaviour and obesity are necessary and important. While they have limitations for understanding many aspects of human behaviour, they nonetheless provide valuable insights and lead the way to potentially novel therapeutic approaches in human subjects. To quote Mary Midgley: 'We are not just rather like animals; we are animals. Our differences from other species may be striking, but comparisons with them have always been, and must be, crucial to our view of ourselves' (Midgley, 1979).

\section{References}

Alcock J (1979) Animal Behaviour: An Evolutionary Approach. Sunderland, MA: Sinauer.

Barsh GS, Farooqi IS \& O'Rahilly S (2000) Genetics of bodyweight regulation. Nature 404, 644-651.

Berridge KC (2004) Motivation concepts in behavioral neuroscience. Physiol Behav (In Press).

Birch LL \& Fisher JO (1998) Development of eating behaviors among children and adolescents. Pediatrics 101, 539-549.

Birch LL, Johnson SL, Andresen G, Peters JC \& Schulte MC (1991) The variability of young children's energy intake. New Engl J Med 324, 232-235.

Bjorntorp P (1997) Body fat distribution, insulin resistance, and metabolic diseases. Nutrition 13, 795-803.

Bouchard C (1995) The genetics of obesity: from genetic epidemiology to molecular markers. Mol Med Today 1, 45-50.

Bray GA (1976) The Obese Patient. Philadelphia, PA: Saunders.

Bray GA (1984) Hypothalamic and genetic obesity: an appraisal of the autonomic hypothesis and the endocrine hypothesis. Int J Obes 8, Suppl. 1, 119-137.

Chapelot D, Marmonier C, Thomas F \& Hanotin C (2000) Modalities of the food intake-reducing effect of sibutramine in humans. Physiol Behav 68, 299-308.

Cigolini M, Seidell JC, Targher G, Deslypere JP, Ellsinger BM, Charzewska J, Cruz A \& Bjorntorp P (1995) Fasting serum insulin in relation to components of the metabolic syndrome in European healthy men: the European fat distribution study. Metabolism 44, 35-40.

Clegg DJ, Benoit SC, Barrera JG \& Woods SC (2003a) Estrogen mediates body fat distribution and brain sensitivity to adiposity signals. Diabetes 52, Suppl. 1, 000-000.

Clegg DJ, Benoit SC, Fisher ME, Barrera JG, Seeley RJ \& Woods SC (2003b) Sex hormones determine body fat distribution and sensitivity to adiposity signals. Appetite 40, 324.

Clegg DJ, Riedy CA, Smith KA, Benoit SC \& Woods SC (2003c) Differential sensitivity to central leptin and insulin in male and female rats. Diabetes 52, 682-687.

Coleman DL (1978) Obese and diabetes: two mutant genes causing diabetes-obesity syndromes in mice. Diabetologia 14, 141-148.

Comuzzie AG \& Allison DB (1998) The search for human obesity genes. Science 280, 1374-1377.

Cone RD (1999) The central melanocortin system and energy homeostasis. Trends Endocrinol Metab 10, 211-216.

De Castro JM (1988) Physiological, environmental, and subjective determinants of food intake in humans: a meal pattern analysis. Physiol Behav 44, 651-659.

De Castro JM (1991) Seasonal rhythms of human nutrient intake and meal pattern. Physiol Behav 50, 243-248.

De Castro JM \& Stroebele N (2002) Food intake in the real world: implications for nutrition and aging. Clin Geriatr Med 18, 685-697.

De Vore I (1971) The evolution of human society. In Man and Beast: Comparative Social Behavior, pp. 297-311 [JF Eisenberg and WS Dillon, editors]. Washington, DC: Smithsonian Institution Press.

Dua A, Hennes MI, Hoffman RG, Maas DL, Krakower GR, Sonnenberg GE \& Kissebah AH (1996) Leptin: A significant indicator of total body fat but not of visceral fat and insulin insensitivity in African-American women. Diabetes 45, 1635-1637.

Galef BG Jr \& Giraldeau LA (2001) Social influences on foraging in vertebrates: causal mechanisms and adaptive functions. Anim Behav 61, 3-15. 
Garofalo RS (2002) Genetic analysis of insulin signaling in Drosophila. Trends Endocrinol Metab 13, 156-162.

Gietzen DW \& Magrum LJ (2001) Molecular mechanisms in the brain involved in the anorexia of branched-chain amino acid deficiency. $J$ Nutr 131, 851S-855S.

Goodman E, Adler NE, Daniels SR, Morrison JA, Slap GB \& Dolan LM (2003) Impact of objective and subjective social status on obesity in a biracial cohort of adolescents. Obes Res 11, 1018-1026.

Grill HJ \& Kaplan JM (2002) The neuroanatomical axis for control of energy balance. Front Neuroendocrinol 23, 2-40.

Grill HJ, Roitman MF \& Kaplan JM (1996) A new taste reactivity analysis of the integration of taste and physiological state information. Am J Physiol 271, R677-R687.

Guarente L \& Kenyon C (2000) Genetic pathways that regulate ageing in model organisms. Nature 408, 255-262.

Hill JO, Wyatt HR, Reed GW \& Peters JC (2003) Obesity and the environment: where do we go from here? Science 299, 853-855.

Ingalls AM, Dickie MM \& Snell GD (1950) Obese, a new mutation in the house mouse. J Hered 41, 317-318.

Lafontan M \& Berlan M (2003) Do regional differences in adipocyte biology provide new pathophysiological insights? Trends Pharmacol Sci 24, 276-283.

Le Magnen J \& Devos M (1982) Daily body energy balance in rats. Physiol Behav 29, 807-811.

Lebovitz HE (2003) The relationship of obesity to the metabolic syndrome. Int J Clin Pract 134, Suppl., 18-27.

Logue AW (1991) The Psychology of Eating and Drinking. New York: Freeman

Midgley M (1979) Beast and Man: The Roots of Human Nature. Brighton, Sussex: Harvester Press.

Mrosovsky N \& Melnyk RB (1982) Towards new animal models in obesity research. Int J Obes Res 6, 121-126.

Powley TL (1977) The ventromedial hypothalamic syndrome, satiety, and a cephalic phase hypothesis. Psychol Rev 84, 89-126.

Rankinen T \& Bouchard C (2002) Genetics and blood pressure response to exercise, and its interactions with adiposity. Prev Cardiol 5, 138-144.

Rodin J \& Marcus JN (1982) Psychological factors in human feeding. Pharmacol Ther 16, 447-468.

Rolls BJ, Engell D \& Birch LL (2000) Serving portion size influences 5-year-old but not 3-year-old children's food intakes. $J$ Am Diet Assoc 100, 232-234.

Rolls BJ, Shide DJ, Thorwart ML \& Ulbrecht JS (1998) Sibutramine reduces food intake in non-dieting women with obesity. Obes Res 6, 1-11.

Schachter S (1968) Obesity and eating. Internal and external cues differentially affect the eating behavior of obese and normal subjects. Science 161, 751-756.
Schachter S (1974) Appetite regulation in obese subjects. Horm Metab Res series 4, 88-91.

Schwartz MW, Woods SC, Porte DJ, Seeley RJ \& Baskin DG (2000) Central nervous system control of food intake. Nature 404, 661-671.

Sclafani A (1989) Dietary-induced overeating. Ann NY Acad Sci 575, 281-289.

Sclafani A (1997) Learned controls of ingestive behaviour. Appetite 29, 153-158.

Seeley RJ \& Moran TH (2002) Principles for interpreting interactions among the multiple systems that influence food intake. Am J Physiol Regul Integr Comp Physiol 283, R46-R53.

Strubbe JH \& Woods SC (2004) The timing of meals. Psychol Rev (In the Press).

Thibault L (2003) Paradoxical effects of a high sucrose diet or effects of nutritional inadequacy? Comment on Goodson et al. Appetite 41, 103.

Thibault L \& Booth DA (1999a) Appetite classics: the role of orosensory and postingestional effects of food in the control of intake: 1956-1963. Jacques Le Magnen. Appetite 33, $1-59$.

Thibault L \& Booth DA (1999b) Macronutrient-specific dietary selection in rodents and its neural bases. Neurosci Biobehav Rev 23, 457-528.

Wajchenberg BL (2000) Subcutaneous and visceral adipose tissue: their relation to the metabolic syndrome. Endocrinol Rev 21, 697-738.

Waterhouse J, Minors D, Atkinson G \& Benton D (1997) Chronobiology and meal times: internal and external factors. Br J Nutr 77, Suppl. 1, S29-S38.

Woods SC, Seeley RJ, Porte DJ \& Schwartz MW (1998) Signals that regulate food intake and energy homeostasis. Science 280, $1378-1383$.

Woods SC, Seeley RJ, Rushing PA, D'Alessio DA \& Tso P (2003) A controlled high-fat diet induces an obese syndrome in rats. $J$ Nutr 133, 1081-1087.

Woods SC \& Strubbe JH (1994) The psychobiology of meals. Psychon Bull Rev 1, 141-155.

World Health Organization (1998) Obesity: Preventing and Managing the Global Epidemic. Geneva: WHO.

Yeo G, Farooqi I, Aminian S, Halsall D, Stanhope R \& O'Rahilly S (1998) A frameshift mutation in MC4R associated with dominantly inherited human obesity. Nat Genet 20, 111-112.

Zhang Y, Proenca R, Maffei M, Barone M, Leopold L \& Friedman JM (1994) Positional cloning of the mouse obese gene and its human homologue. Nature 372, 425-432.

Zucker LM \& Zucker TF (1961) Fatty, a new mutation in the rat. $J$ Hered 52, 275-278. 